\title{
A Study of Hydrous Ethanol Combustion in an Optical Central Direct Injection Spark Ignition Engine
}

\author{
Mohammadmohsen Moslemin Koupaie, Alasdair Cairns. University of Nottingham \\ Hassan Vafamehr. Brunel University London \\ Thompson Diordinis Metzka Lanzanova. Federal University of Santa Maria
}

\begin{abstract}
The aim of this experimental work was to improve understanding of the influence of hydrous ethanol on combustion in an engine demonstrating a tendency for biased flame migration towards the hotter exhaust walls as often reported for typical modern pent roof design IC engines. The work aimed to uncover the degree of residual water content that can be reasonably tolerated in terms of combustion characteristics in future ethanol SI engines (with the energy required to reduce water levels then potentially reduced). The experiments were performed in a single cylinder optical research engine equipped with a modern central direct injection combustion chamber and Bowditch type optical piston. Results were obtained under part-load engine operating conditions (selected to represent typical highway cruising conditions) with hydrous ethanol at $5 \%, 12 \%$ and $20 \%$ volume water. Baseline results were obtained using pure isooctane. High-speed cross-correlated particle image velocimetry was undertaken at 1500rpm under motoring conditions with the intake plenum pressure set to 0.5 bar absolute. The horizontal imaging plane was fixed $10 \mathrm{~mm}$ below the combustion chamber "fire face". Comparisons were made to CFD computations of the in-cylinder flow. Complimentary flame images were obtained via the "natural light" (chemiluminescence) technique over multiple engine cycles. The flame images revealed the tendency of an iso-octane fueled flame to migrate towards the exhaust side of the combustion chamber, with no complimentary bulk air motion apparent in this area in the horizontal imaging plane. The faster-burning ethanol offset this tendency of the flame to migrate towards the hotter exhaust walls. The fastest combustion rate occurred with pure ethanol, with higher water content $(>5 \%)$ generally slowing down the flame speed rate to $10.64 \mathrm{~m} / \mathrm{s}$ from 10.92 of ethanol and offsetting the flame speed/migration benefit (in good agreement with recent laminar burning velocity correlations for hydrous ethanol). When adding $20 \%$ water to ethanol the combustion rate was significantly slower $(8.2 \mathrm{~m} / \mathrm{s})$ with a considerable increase in flame shape distortion as quantified by flame image shape factor values. The results demonstrate how the added water increases flame distortion and leads to higher flame centre displacement. Such flame centre displacement could potentially be offset in the future with a spark plug location biased further towards the intake side of the chamber (albeit sometimes practically constrained by the priorities given to intake valve sizing and local cooling jacket design). The results indicate that ethanol fuels offset such bias flame growth and allow residual water to be tolerated for an equivalent degree of biased flame migration. The implication is reduced fuel production energy and cost required to produce usable ethanol fuels.
\end{abstract}


KEYWORDS: Hydrous ethanol, Direct-injection spark-ignition engines, PIV, CFD, High-Speed Imaging, Flame distortion.

\section{INTRODUCTION}

The recent increase in biofuel usage for automotive applications is primarily the result of continuing efforts to reduce carbon footprint, in order to achieve the transition to a GHG-free world economy, as described in the Paris protocol climate agreement [1]. In addition, battery-powered electric vehicles were proposed to achieve this purpose, however barriers exist such as lack of infrastructure, slow charging processes and short driving range [2]. Some recent large scale studies within Germany have proposed E-fuels as an alternative for mobility [3,4]. E-fuels are produced via renewable energy and use the same infrastructure of today's fuel and can be used by the existing stock of passenger and utility vehicles [5]. Ethanol produced from diverse agricultural crops has been chosen as both a substitute and additive to gasoline due to a profitable production process, lower carbon footprint and potential for production via renewables. First generation bioethanol was largely produced from fermented sugars from diverse agricultural crops but efforts continue to produce such fuels from more sustainable sources such as refuse, cellulosic materials and algae [2].

During the ethanol production process, irrespective of the crop used, the resulting mixture from the fermentation process contains more than $85 \%$ volume of water [6]. Distillation can be used to separate this water until the mixture reaches the azeotropic point (approximately 94\% ethanol-in-water v/v, so-called hydrous ethanol). Subsequently, diverse dehydration techniques can be used to obtain anhydrous ethanol (99\% ethanol, or purer). A large quantity of energy is expended during the distillation and dehydration processes in order to remove the water, especially after the mixture reaches around $80 \%$ of ethanol-in-water [7]. For this reason, several researchers have studied the best compromise between net energy gain during the ethanol production process and water-inethanol content from different crops and production processes [8-11]. From such studies, it can be deduced that the best compromise is between $80 \%$ and $90 \%$ of ethanol-in-water (v/v) based upon net gain.

It follows that the direct use of "wet" ethanol (ethanol-in-water mixtures with less than $95 \%$ ethanol v/v) in spark ignition engines have attracted recent interest. In general, the higher water content acts as a diluent and requires more advanced spark timing to reach MBT (Minimum spark advance for Best Torque)[11,12]. The Flame Development Angle (FDA), combustion duration and heat release rates also deteriorate as a result of lower combustion temperatures[13-15]. As a result, the unburned fuel fraction, aldehyde emissions and other hydrocarbon emissions can be increased with increased water content [16]. In addition to increased emissions, the application of high water-in-ethanol content mixtures in vehicles may have the energy and environmental impact 
benefits counterbalanced by worse specific fuel consumption with the issues of water separation in flex-fuel gasoline blends [17]. In practical terms, hydrous ethanol may be more suitable for future dedicated ethanol SI engines, where modern central direct injection systems can overcome the challenges associated with the cold start of E100 [9].

Combustion imaging was recently performed elsewhere to better understand the effects of increased water content on the ethanolfueled spark ignition combustion process [18]. Both port and direct fuel injection were studied for mixtures with up to $10 \%$ water v/v. Combustion duration increased for higher ethanol-in-water content and shortened under PFI operation. DI operation resulted in a higher level of droplet diffusion burning in the flame development images when compared to PFI operation. The optical results showed that the increase in water content decreased the flame distortion and corrugation. Flame growth rate behaviour was in good agreement with laminar flame speed studies, where the increased water-in-ethanol content decreased the flame speed and reduced burning rates[19,20].

Lately, wet ethanol with $20 \%$ of water content has been used to increase thermal stratification in a diesel engine to extend HCCI load range in a diesel engine [21-23]. The conventional diesel injector was used with split wet ethanol injections. A small amount of wet ethanol injected into the cylinder during compression has a strong ability to lower the peak heat release rates. Engine efficiency was comparable to that of HCCI engine operation. Elsewhere[24], several compression ratios were tested in a naturally aspirated SI PFI test engine to investigate the possible gains from the use of wet ethanol. The engine could run up to full load with a compression ratio of $14.5: 1$ and $20 \%$ of water-in-ethanol content. This reduced engine-out emissions compared to lower compression ratios and resulted in higher indicated efficiency compared to hydrous ethanol operation (4\% of water-in-ethanol v/v content). Thus, recent advances in variable compression ratio technologies [25,26] may enable the use of advanced combustion concepts for passenger cars using cheap wet ethanol (compared to anhydrous ethanol) .

The contribution of the currently work is to better characterize hydrous E-fuels such as ethanol in a central direct injection spark ignition engine through flow and combustion visualization techniques. Several flame related parameters, such as shape factor and apparent flame speed, are discussed and compared with the flow and heat release analysis. The optical experiments in the currently reported study showed a 5\% increase in water content increased flame distortion marginally (5.84\%) when compared to pure ethanol. Moreover, a 12\% water blend ("W12E88") and 20\% water blend (W20E80) increased flame distortion notably. The increase in water content in ethanol has been associated with lower peak temperatures and slower combustion rates [27]. The aim of the currently reported study was to improve understanding and specifically quantify the direct influence of such water on the flame propagation event in terms of apparent bulk flame distortion and migration, with associated flow data available to aid qualification of the interaction of the flame and flow. 


\section{EXPERIMENTAL ARRANGEMENT}

\section{ENGINE SETUP AND FUELS}

A customized single cylinder Direct Injection Spark Ignition (DISI) optical engine was used in this study. The key features of the engine geometry are set out in Table 1, with corresponding optical engine schematics presented in Figure 1. The cylinder head had a "pent-roof" combustion chamber design with centrally mounted spray-guided direct injection using an outward opening piezoactuated fuel injector adopted in production and installed following manufacturer guidelines [28]. The engine was fitted with a relatively "neutral" intake port (without any sharp inner corner radius associated with high tumble engine designs). The four valves were operated by double overhead camshafts in an aluminum cylinder head. The bottom-end was based on a Ricardo Hydra, mounted on a $30 \mathrm{~kW}$ Cussons test bed with integrated oil and coolant control $\left( \pm 2^{\circ} \mathrm{C}\right.$ tolerance). The Hydra was fitted with a customized cast iron block, wet liner, and a Bowditch piston. The Bowditch piston allowed a $45^{\circ}$ mirror to be placed inside the hollow core providing optical access to the combustion chamber through a flat quartz piston crown. The extended piston was made of aluminum, with PTFE compression rings lubricated with grease. The flat-topped piston crown window had a 55mm diameter, allowing approximately $50 \%$ of the bore area to be visualized. The visible area is shown in Figure 2. A sandwich plate was designed to connect the cylinder head and the extended block with two additional side windows ( $21 \mathrm{~mm}$ height) providing additional optical access to the combustion chamber. The windows were used to guide the PIV laser light through the combustion chamber at the piston position of $30^{\circ} \mathrm{CA}$ BTDC firing. The laser sheet was aligned horizontally $5 \mathrm{~mm}$ above the optical piston and $10 \mathrm{~mm}$ below the spark plug. A key limitation of the design was the enlargened piston top land crevice volume as illustrated in Figure 1. This resulted in relatively high blow-by and slow end of mass burning as some fuel-air charge returned to the main chamber during the power stroke.

Table 1. Key engine specifications.

\begin{tabular}{|l|l|}
\hline Displaced volume & $447 \mathrm{cc}$ \\
\hline Stroke & $89 \mathrm{~mm}$ \\
\hline Bore & $80 \mathrm{~mm}$ \\
\hline Compression ratio & $8.67: 1$ \\
\hline Inlet vales diameters & $29.5 \mathrm{~mm}$ \\
\hline Exhaust valves diameters & $21 \mathrm{~mm}$ \\
\hline Valve lift & $9 \mathrm{~mm}$ \\
\hline Cam duration (Exhaust, Intake) & $220^{\circ} \mathrm{c}$. a. (end of ramp) \\
\hline EMOP & $265^{\circ}$ ATDC (compression) \\
\hline IMOP & $455^{\circ}$ ATDC (compression) \\
\hline Engine Coolant temperature & $90^{\circ} \mathrm{C}$ \\
\hline Injection timing & $270^{\circ} \mathrm{CA} \mathrm{BTDC} \mathrm{firing}$ \\
\hline Engine Speed & 1500 RPM \\
\hline
\end{tabular}


The piezo-actuated fuel injector used in the experiments sprayed a $90^{\circ}$ fuel cone directly in front of the spark plug (with the injector installation optimized to the injector manufacturer guidelines). The fuel supply system consisted of a PowerStar4 double ended air driven pump with an amplification ratio of 64:1. Using an air pressure regulator, the injection pressure for the tests was set to 100 bar. The pressure variation in the fuel rail was measured to be \pm 2 bar at 100 bar fuel pressure.

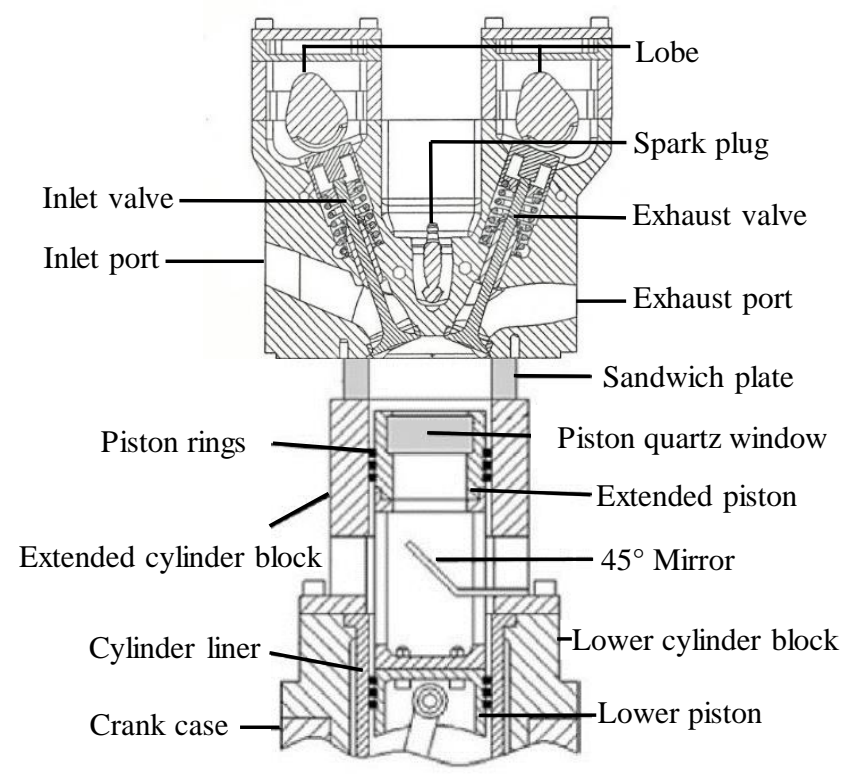

Figure 1. Engine setup schematic.

Three fuels were compared to iso-octane and pure ethanol: an ethanol blend containing 5\% water and 95\% ethanol (W5E95), 12\% water and 88\% ethanol (W12E88) and 20\% water and 80\% ethanol (W20E80). Some of the key properties of the component fuels are set out in Table 2. The laminar burning velocities were taken from recent literature [29],[30] and [31-34], being obtained at stoichiometric conditions. It is apparent that differences amongst fuels at high pressure are quite small. Although experimental uncertainties of the order $1 \mathrm{~cm} / \mathrm{s}$ typically exist, there is a general decrease in burning velocity with decreasing pressure and increase with temperature (and carbon chain length for the alcohols).

During the firing experiments, a typical start-of-injection timing of $60^{\circ}$ Crank Angle (CA) after intake Top Dead Centre (ATDC) was adopted for 'homogeneous' mixture preparation. Pulse width durations of $0.78 \mathrm{~ms}, 0.83 \mathrm{~ms}, 0.85 \mathrm{~ms}$, and $0.95 \mathrm{~ms}$ were used for ethanol, W5E95, W12E88 and W20E80 respectively to attain stoichiometric combustion at the same throttle position. The fuelling was monitored using a Horiba-mexa-110 $\lambda$ air/fuel ratio measurement system with a commercial wideband Lambda sensor, which allowed the user to input the $\mathrm{C} / \mathrm{H} / \mathrm{O}$ ratio for each fuel. Injection duration was measured with an oscilloscope, triggered after SOI (start of injection). The time interval is mentioned in the table and reflects the heating value of each fuel. 
Table 2. Fuel properties.

\begin{tabular}{|l|l|l|l|l|l|}
\hline Fuel parameters & Ethanol & W5E95 & W12E88 & W20E80 & Iso-octane \\
\hline Density $20^{\circ} \mathrm{C}\left[\mathrm{g} / \mathrm{cm}^{3}\right]$ & 0.79 & 0.80 & 0.85 & 0.89 & 0.69 \\
\hline Density $80^{\circ} \mathrm{C}\left[\mathrm{g} / \mathrm{cm}^{3}\right]$ & 0.73 & 0.75 & 0.8 & 0.84 & 0.64 \\
\hline Heating value $[\mathrm{MJ} / \mathrm{kg}]$ & 26.9 & 24.06 & 22.01 & 18.78 & 44.6 \\
\hline $\begin{array}{l}\text { Laminar burning velocity at } \\
\text { equivalence ratio }(\phi) \text { of } 1,[\mathrm{~cm} / \mathrm{s}]\end{array}$ & $65^{\mathrm{b}}$ & $62.5^{\mathrm{c}}$ & $60^{\mathrm{c}}$ & $55^{\mathrm{b}}$ & $30^{\mathrm{d}}$ \\
\hline Injection duration, $[\mathrm{ms}]$ & 0.78 & 0.83 & 0.85 & 0.95 & 0.52 \\
\hline
\end{tabular}

a) If not specified, data taken from product data sheets.

b) Taken from [31].

c) Interpolated from [31,32].

d) Taken from [33,34].
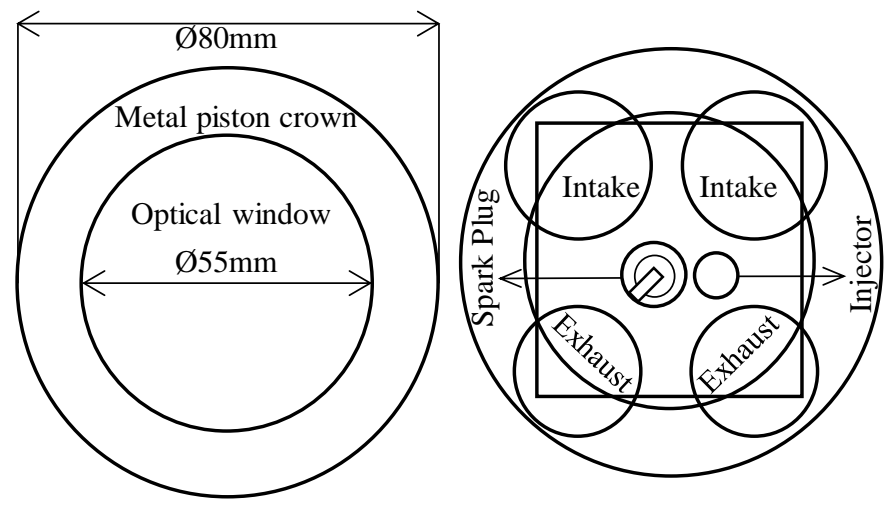

Figure 2. Combustion chamber and Piston crown.

\section{PIV EXPERIMENTAL IMPLEMENTATION}

The laser unit used for the PIV experiments was a NANO L 135-15 PIV laser supplied by Litron Lasers. The laser unit was powered by an LPU 450 power station configured to drive two laser units with a $450 \mathrm{~W}$ combined throughput. The laser head consisted of two $1064 \mu \mathrm{m}$ laser units, half wave plates, mixing and steering polarizers and a harmonic generator. The laser head supplied $532 \mu \mathrm{m}$ laser beams with up to $136 \mathrm{~mJ}$ laser pulse energy under a $160 \mu$ s optimized Q-switch delay. The images of flow with seeding particles were captured using a Dantec Dynamic FLOWSENSE 4M Camera system with an ICCD camera of 2048x2048 pixels, which had a minimum inter-frame time of 200ns. The lens used for the PIV test was an UV-Nikkor $60 \mathrm{~mm}$ lens. A 532nm narrow band filter was also used to remove background light.

A non-toxic, non-corrosive, non-abrasive, non-volatile and chemically inert vegetable oil (density $910 \mathrm{~kg} / \mathrm{m} 3$ ) was selected as the PIV seeding particle. Its properties enabled it to provide minimum drag impact and yet scatter enough light for the PIV measurements. A 10F03 seeding generator supplied by Dantec Dynamics was used. The equipment was set to supply seeding flow 
with an average droplet size of Sauter Mean Diameter (SMD) $2 \mu \mathrm{m}$ to $3 \mu \mathrm{m}$ up to a pressure of 3 bar. The seeding was supplied downstream of the throttle plate, the frequency and amplitude response of a particle of that density and size was calculated on the basis of its relaxation time [35] and it was found to be able to respond appropriately to fluctuations up to a range of $\sim 5-7 \mathrm{kHz}$.

The PIV processing was undertaken using the commercial platform Dynamic Studio. A MATLAB code was developed to post process and calculate the average cycle images with arrow size scaled in respect to velocities using a quiver function. A detailed explanation of this PIV function has previously been fully presented in [36,37] so only a brief explanation will be provided here. The images with the flow seeding particle position information were divided into a number of square interrogation areas depending on many factors. The velocity vector evaluation of each interrogation area was calculated using the cross-correlation method. For this PIV experimental setup, a 32x32 pixels interrogation area was used combined with the Gaussian algorithm, which corresponds to a spatial resolution of $1.8 \mathrm{~mm} \times 1.8 \mathrm{~mm}$. The PIV was measured at compression stroke crank angles of $30^{\circ}, 40^{\circ}, 90^{\circ}$ and $180^{\circ} \mathrm{CA}$ BTDC for a low load engine operating condition at $1500 \mathrm{rpm}(0.5$ bar absolute plenum pressure).

\section{HIGH-SPEED IMAGING}

A NAC MEMRECAM fx 6000 high-speed video camera coupled to a DRS Hadland Model ILS3-11 image intensifier was used to record all-optical data. The camera was synchronized with a DAQ to record images simultaneously with the pressure data. The camera was set to record $6000 \mathrm{fps}$ resulting in time-resolved images every $1.5 \mathrm{CAD}$ at a resolution of 512 x 384 pixels. In line with industry practice, 300 thermodynamic results were obtained with each run, with 60 visual cycles obtained due to camera internal memory limitations. This was considered an acceptable compromise as both this work and others have shown that 50 cycles may bottom out the bulk of variation [38].

The lens used for the high-speed imaging test was an UV-Nikkor $105 \mathrm{~mm}$ lens. An intensifier intensity sweep was undertaken to determine the optimal compromise between image intensity and noise level. It was concluded that $80 \%$ of the maximum intensifier capacity was required to provide sufficient flame intensity under the stoichiometric conditions examined (determined by evaluating the computed flame radius in a repetitive manner to ensure repeatability).

\section{FLAME IMAGE PROCESSING}

Once the combustion cycles were captured as a concurrent set of images they were downloaded in TIFF format. An in-house MATLAB script was developed to batch process the files, converting each TIFF to a black and white image. A dynamic masking process was applied to remove any 'halo' effect from the bore. Finally, the image was inverted into black and white and the visible area circle was applied. These stages are laid out visually in Figure 3.

To calculate the inflamed area of each image, the matrix that forms the binary image was simply summed to a single number that represented the area of the flame in square-pixels. Since the diameter of the imaging area was known $(55 \mathrm{~mm})$ in terms of both the 
number of pixels in the image and the real diameter in millimeters, the area in square pixels could be easily converted into squaremillimeters.

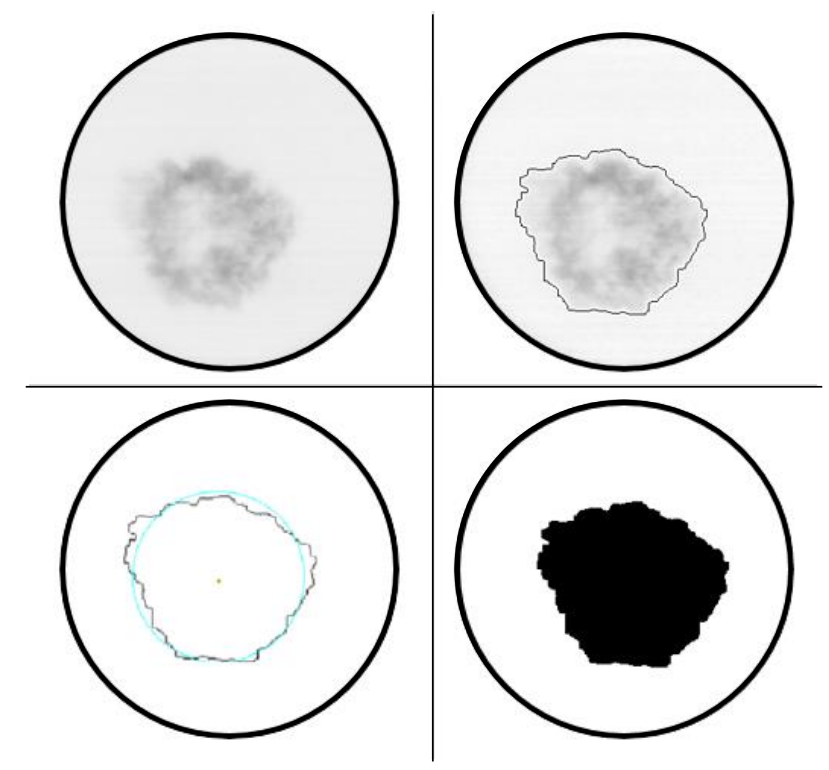

Figure 3. Illustration of the flame image processing procedure.

The flame centroid was identified by locating the point at which a centre of "mass" would be situated considering the inflamed area as a solid object. For the finite set of pixels $\left(p_{x}\right)$ throughout the image, the centroid is:

$c=\sum \frac{p_{x}}{k}$

where $\mathrm{k}$ is the number of pixels selected in the image and $p_{x}=\left(x_{i}, y_{i}\right)$ the Euclidean co-ordinates of the pixels.

The flame radius was calculated by considering that the amount of unburned charge encompassed by a circle with such radius would be equal to the amount of burned charge [38]. Figure 3 shows both the best-fit circle (Cyan) and the flame contour (Black) for an individual image in a cycle with flame perimeter and area also shown. To define the influence of the bulk air motion, the shape factor was also calculated as the ratio of the actual flame perimeter length to that of a circle encapsulating an equivalent area [38].

The apparent flame speed was calculated using the changing distance (radius) over the time step between images and can be defined as the sum of the turbulent entrainment velocity and the velocity at which the unburned gas is pushed away by compression due to piston motion and the expanding burned gas.

FLOW AND FLAME IMAGING RESULTS 
It is crucial to have statistically robust calculations when considering a highly turbulent environment and the associated cyclic variations in the flow within an IC engine. In order to quantify the 'ensemble mean' flow field and turbulent flow parameters, 1500 cycles were selected at $30^{\circ} \mathrm{CA}$ BTDC and randomly divided into 15 batches using MATLAB rand code, with each batch containing 100 cycles. Full details of the procedure have been provided in a previous publication [37]. It was concluded that the highest variation from 100-1500 cycles was $10 \%$ for turbulence intensity and $8.5 \%$ for average velocity. Hence from previous work [37,39] along with storage and time issues, 800 cycles were considered an appropriate total.

\section{PIV AND CFD ON HORIZONTAL PLANE}

To understand the behavior of the in-cylinder bulk flow, PIV images were divided into four zones (denoted as I1, I2, E1, E2) with the inlet valves on the top and exhaust valves on the bottom side. Vector fields between $180^{\circ} \mathrm{CA}$ BTDC and $30^{\circ} \mathrm{CA}$ BTDC cover the period that the air was being compressed in the cylinder with both valves closed until top dead centre. Shown in Figure 4 are mean velocity fields compared with the corresponding k- $\varepsilon$ RNG CFD result. In general, the air flow structure visible from the optical window of the piston crown follows coherent discernable patterns that visually correlate reasonably well with the CFD results. Furthermore, for this plane, it can be seen that two major vortices appear (albeit important to note the centre of these structures were at the edges of the PIV plane).

Table 3. Turbulence intensity measured at $30^{\circ}, 40^{\circ}, 90^{\circ}$ and $180^{\circ} \mathrm{CA}$ BTDC in 4 zones.

\begin{tabular}{|l|l|l|l|l|}
\hline & $180^{\circ} \mathrm{BTDC}$ & $90^{\circ} \mathrm{BTDC}$ & $40^{\circ} \mathrm{BTDC}$ & $30^{\circ} \mathrm{BTDC}$ \\
\hline Zone $\mathrm{I}_{1}$ & 1.24 & 1.20 & 1.17 & 1.12 \\
\hline Zone $\mathrm{I}_{2}$ & 1.19 & 1.18 & 1.20 & 1.17 \\
\hline Zone $\mathrm{E}_{1}$ & 1.22 & 1.16 & 1.21 & 1.11 \\
\hline Zone $\mathrm{E}_{2}$ & 1.13 & 1.17 & 1.18 & 1.14 \\
\hline
\end{tabular}

It can be seen from Table 3 that in each zone the values for turbulence intensities were very close, which emphasizes the fact that there was no bulk flow motion toward any side of the piston. This fact can also be seen within the CFD result although some caution is required given the idealized nature of the modelling approach. Further details on the CFD and PIV setup and procedures can be found in previously published work [37]. 


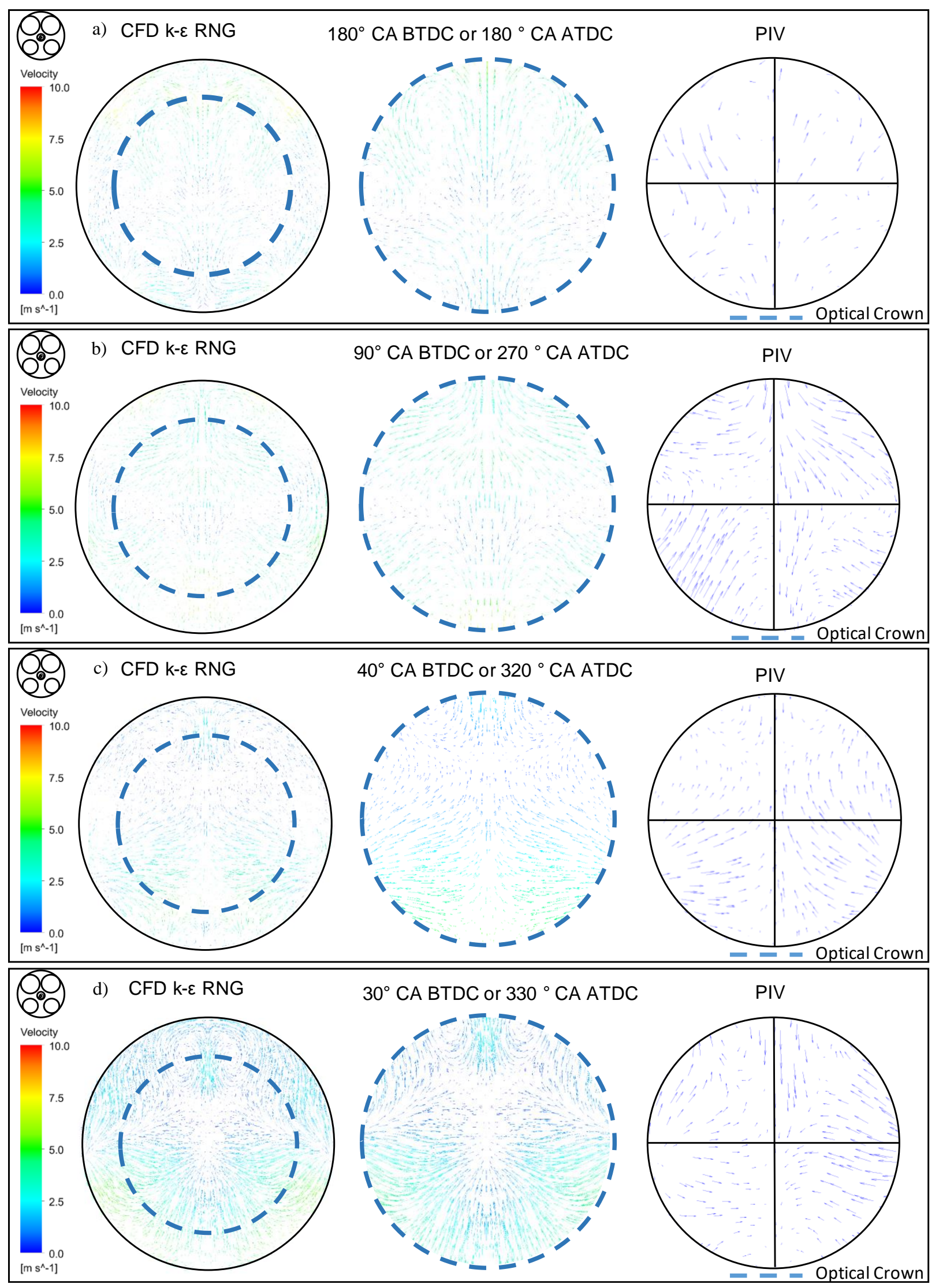

Figure 4. Mean velocity fields on the horizontal plane for CFD and PIV images. 


\section{COMBUSTION STABILITY AND CYCLE VALIDATION}

In order to compare the cyclic variations and combustion characteristics of the fuels, a procedure was adopted to allow selection of real cycles representative of typical fast, mean and slow flame development events. This procedure has also been described in a past publication [37]. When examining in-cylinder pressure data alone, with a sample size of 300 cycles it was generally observed that no single real cycle would exhibit in-cylinder pressure development identical to that of the arithmetic mean pressure profile computed over the data set. This observation is in good agreement with the prior related observations of Moxey [38],[40]. Hence it was crucial to manually select a real cycle whose pressure development was closest to the averaged cycles. This was considered to be a robust method when comparing different fuels albeit still reliant on manual selection of the nearest cycles.

The Net IMEP and combustion stability for the fixed spark timing at $40^{\circ} \mathrm{CA}$ BTDC (which corresponded to MBT for the fasted burning pure ethanol fuel) are shown in Figure 5 in terms of Net IMEP and combustion stability values from a cycle closest across the full 300 cycles. As the heating value and the injected mass are not the same for the three fuels, the net IMEP is also normalized with the input energy. The spark timing was fixed at the MBT value for the fastest fuel to avoid any over-advancement. Presented in Figure 6 are the heat release rate values for 5 fuels, indicating pure ethanol as the fastest burning fuel and W20E80 as the slowest fuel.

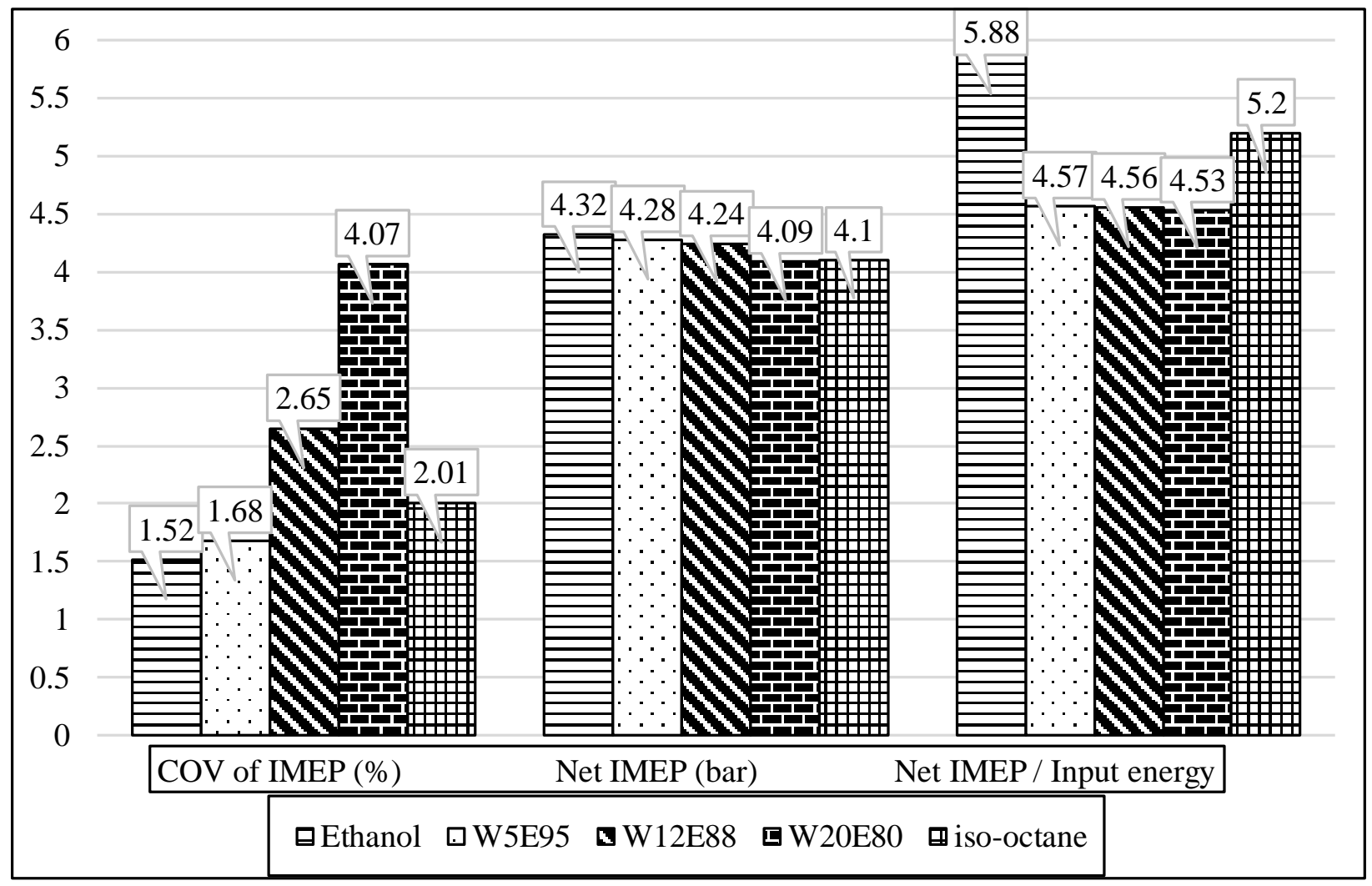

Figure 5. Net IMEP and combustion stability values from the cycles closest to the mean (300 cycles) under MBT fix spark timing condition. 


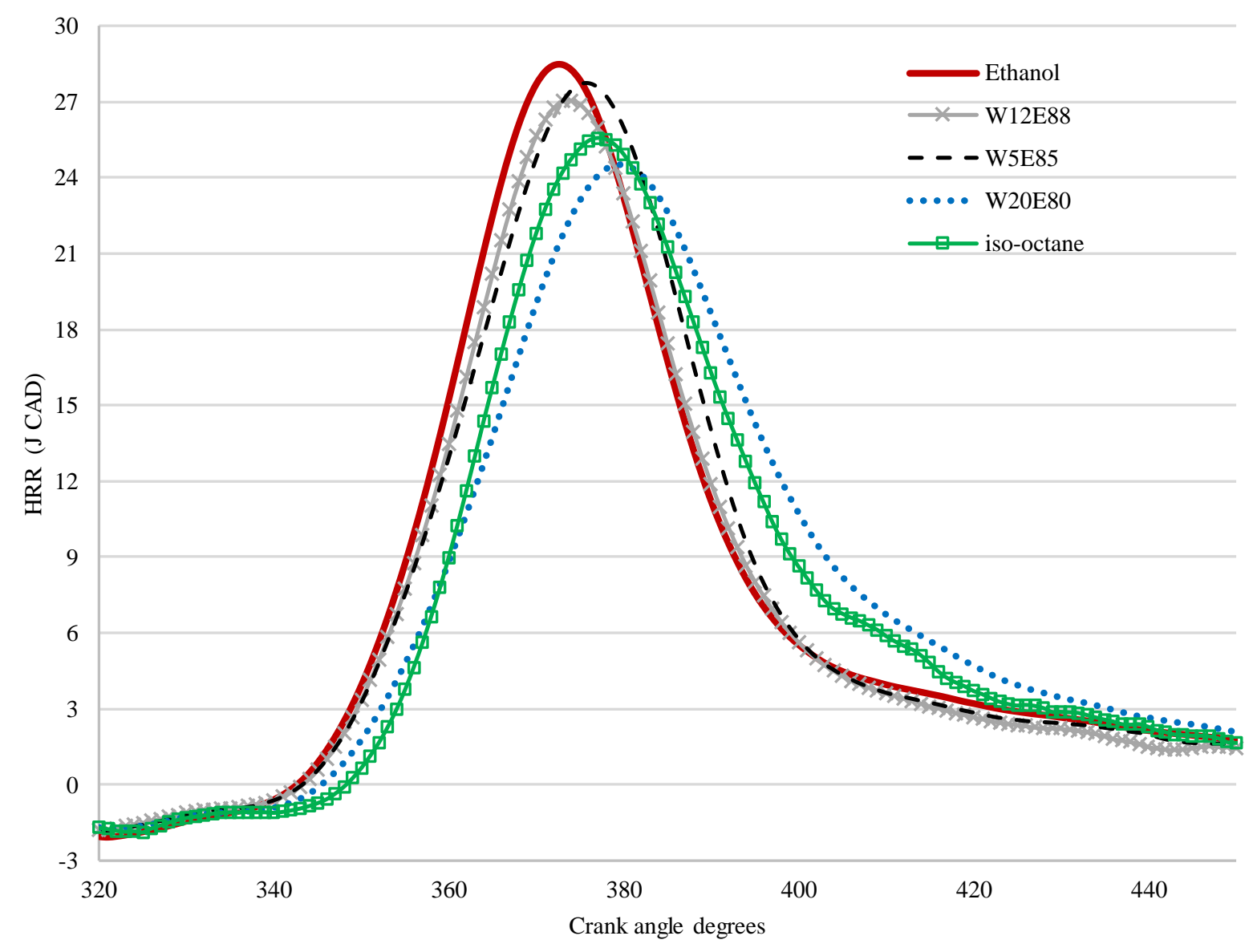

Figure 6300 cycles average heat release rate for all fuels (Fixed spark timing).

Presented in Table 4 are the key mean combustion parameters for ethanol, W5E95, W12E88, W20E80 and iso-octane for 300 cycles. Ethanol exhibited a maximum pressure of 20.3 bar that was approximately $5 \%$ and 24\% higher than W5E95 and W20E80 respectively. As the fastest burning fuel, it was noted to reach the crank angle timing of maximum pressure and crank angle of 50\% mass fraction burned sooner, with the lowest CA_Pmax and CA50 values compared to hydrous ethanol.

Table 4. Mean key combustion parameters of ethanol and hydrous ethanol for 300 cycles.

\begin{tabular}{|l|l|l|l|l|l|}
\hline Parameter & Ethanol & W5E95 & W12E88 & W20E80 & Iso-octane \\
\hline Pmax & $20.37 \mathrm{bar}$ & $19.15 \mathrm{bar}$ & 18.45 & 16.37 & $18.17 \mathrm{bar}$ \\
\hline CA_Pmax & $18^{\circ}$ ATDC & $19^{\circ}$ ATDC & $21^{\circ}$ ATDC & $21^{\circ}$ ATDC & $19^{\circ}$ ATDC \\
\hline CA50 & $6^{\circ}$ ATDC & $6^{\circ}$ ATDC & $7^{\circ}$ ATDC & $12^{\circ}$ ATDC & $9^{\circ}$ ATDC \\
\hline $0-10$ MFB duration & $12 \mathrm{CAD}$ & $12 \mathrm{CAD}$ & $13 \mathrm{CAD}$ & $17 \mathrm{CAD}$ & $15 \mathrm{CAD}$ \\
\hline $10-75$ MFB duration & $16 \mathrm{CAD}$ & $17 \mathrm{CAD}$ & $18 \mathrm{CAD}$ & $23 \mathrm{CAD}$ & $20 \mathrm{CAD}$ \\
\hline
\end{tabular}

\section{COMBUSTION AND FLAME CHARACTERISTICS RESULTS}


Set out in Figure 7 and Figure 8 are comparisons of the in-cylinder pressure data for the mean (Figure 7) fastest and slowest (Figure 8) cycle for each fuel under fixed spark timing of ethanol at MBT showing the small difference between ethanol and W5E95 (and a notable difference comparing Ethanol to W20E80). Here the small differences observed in
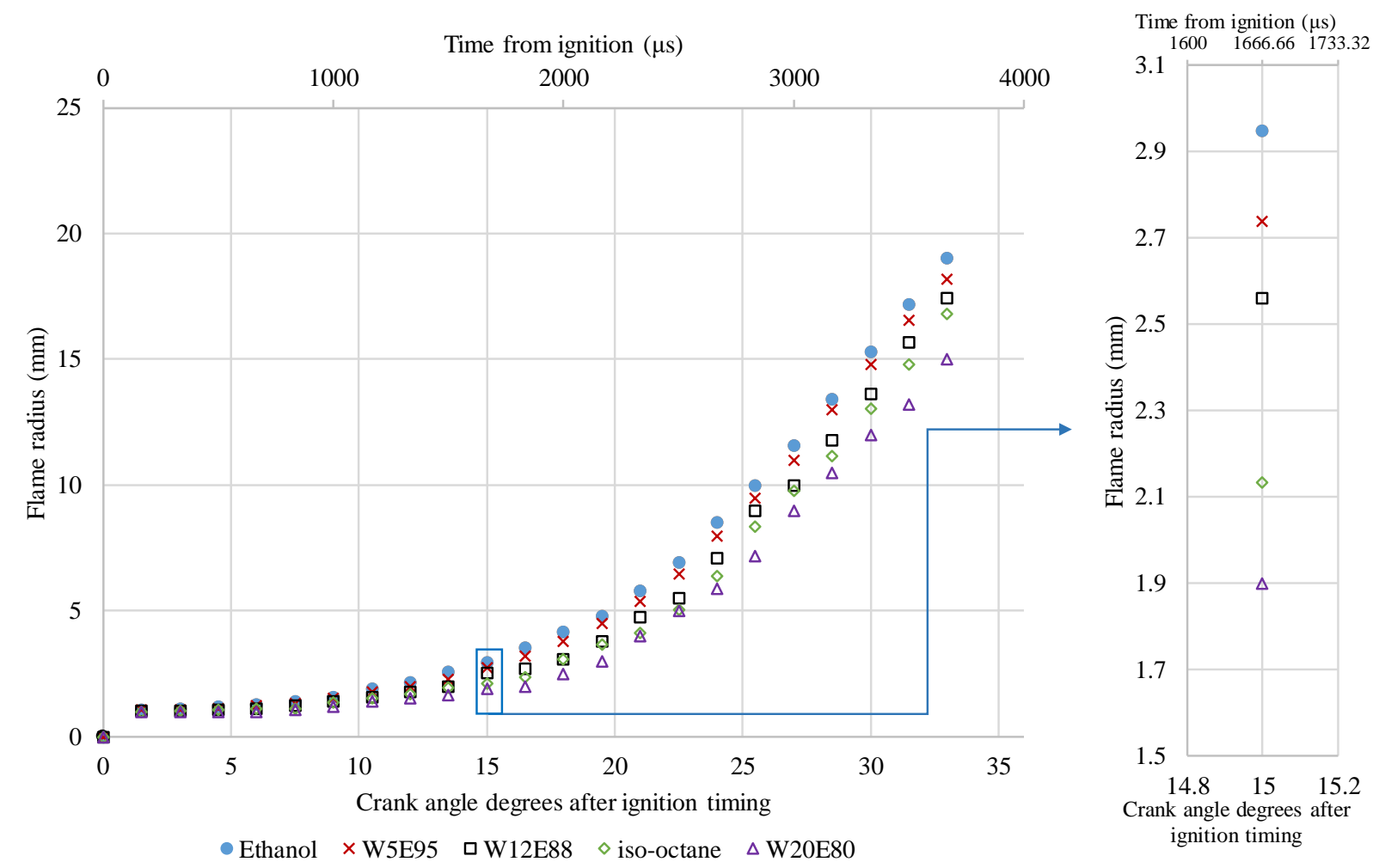

Figure 9 for the mean flame development become more pronounced, where the slower burning W20E80 and W12E88 cases presented wider bands of in-cylinder pressure development (in terms of the observed range of CA_Pmax rather than examining such deviation in the broader terms of COV of IMEP). Shown in Figure 9 is the mean flame radius development for ethanol, W5E95, W12E88, W20E80 and iso-octane. The maximum limit for flame radius in this figure is the optical piston window restriction of $27.5 \mathrm{~mm}$ radius (and by considering flame stretching the maximum flame radius was reached to $19.05 \mathrm{~mm}$ ). The flame centroid displacement towards the hotter side of the chamber should also be noted. The maximum flame radius reduces to $19.05,18.20,17.45,15$ and $17.13 \mathrm{~mm}$ for ethanol, W5E95, W12E88, W20E80 and iso-octane respectively. The flame radius development rate for the ethanol and W5E95 fuels was very similar within 5 CAD after ignition timing and exhibited a notably faster initial flame radius in the period of 0-7 CAD AIT. Overall, ethanol was the fastest propagating fuel followed by W5E95, W12E88, iso-octane and W20E80. This seems to be in accordance with burning velocity correlations for iso-octane, ethanol, and hydrous ethanol e.g. [41]. 


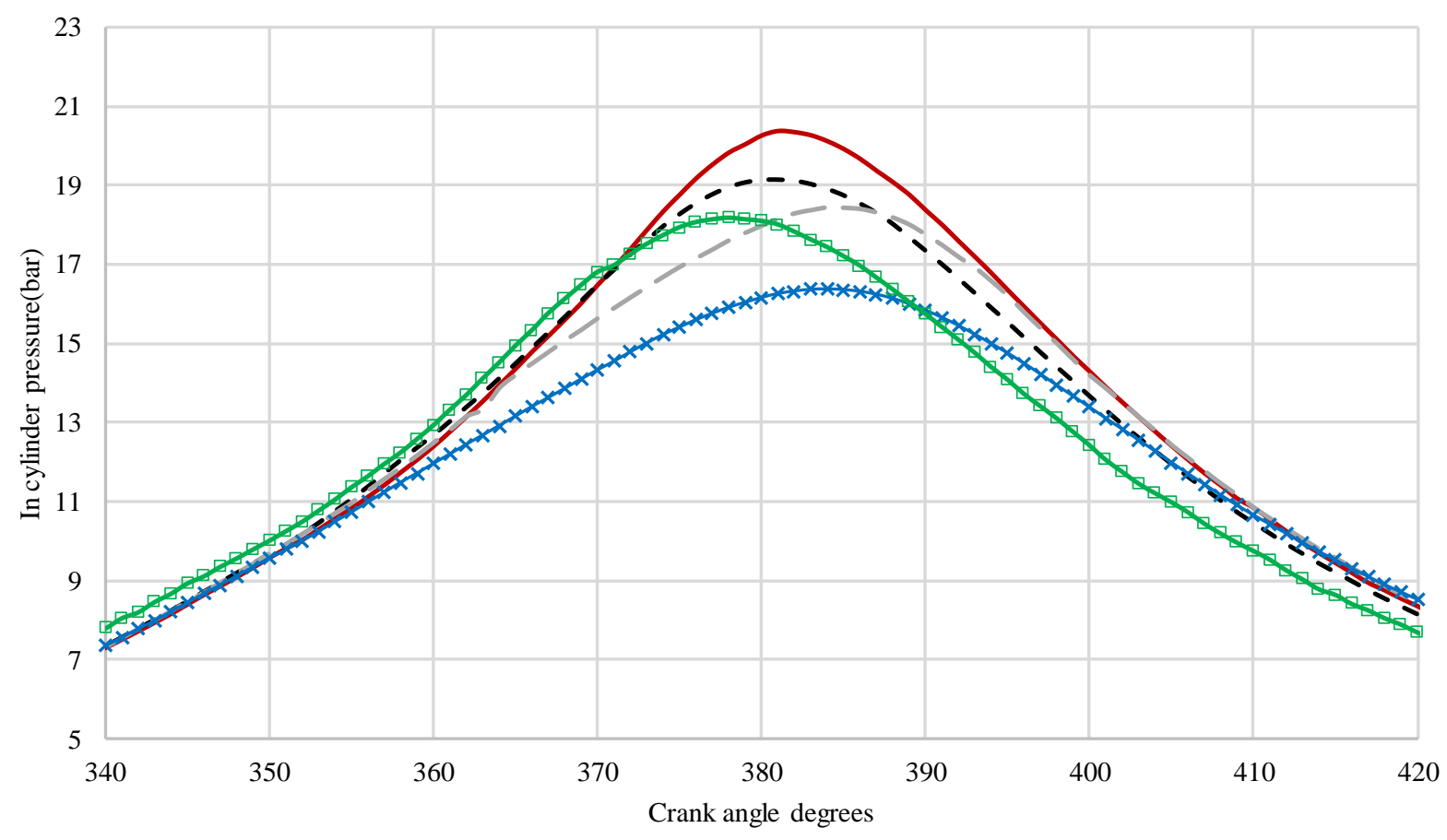

$\longrightarrow$ E100 - - W5E95 - W12E88 $\rightarrow$ W20E80 $\square$ iso-octane

Figure 7. 300 combustion cycles displayed with the cycles closest to numerical mean at fixed spark timing at 1500 rpm and 4 bar IMEP.

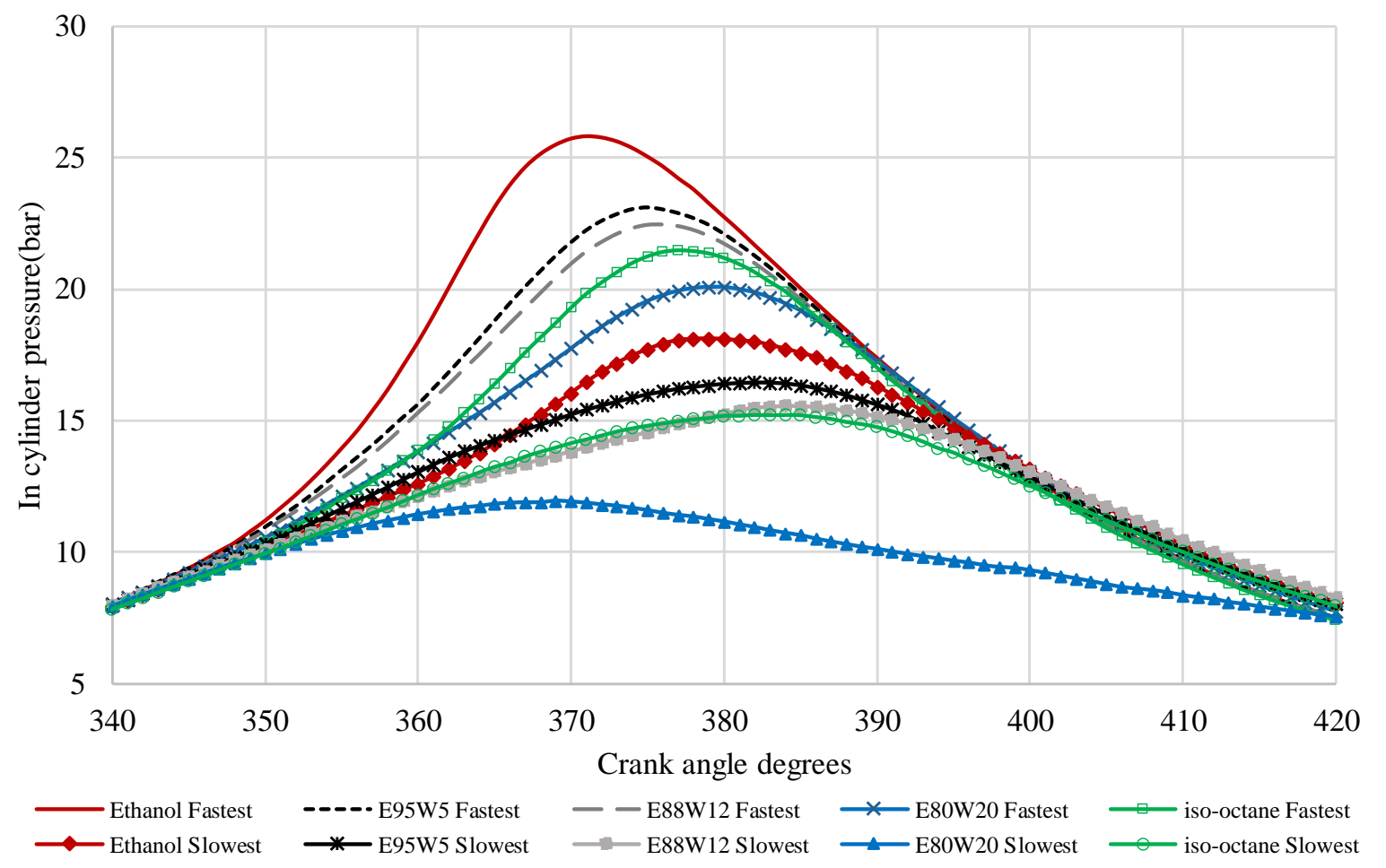

Figure 8. Experimental in-cylinder pressure data (60 cycles) for the relevant fastest and slowest cycles; taken from combustion under stoichiometric conditions, (Ethanol, MBT spark timing). 

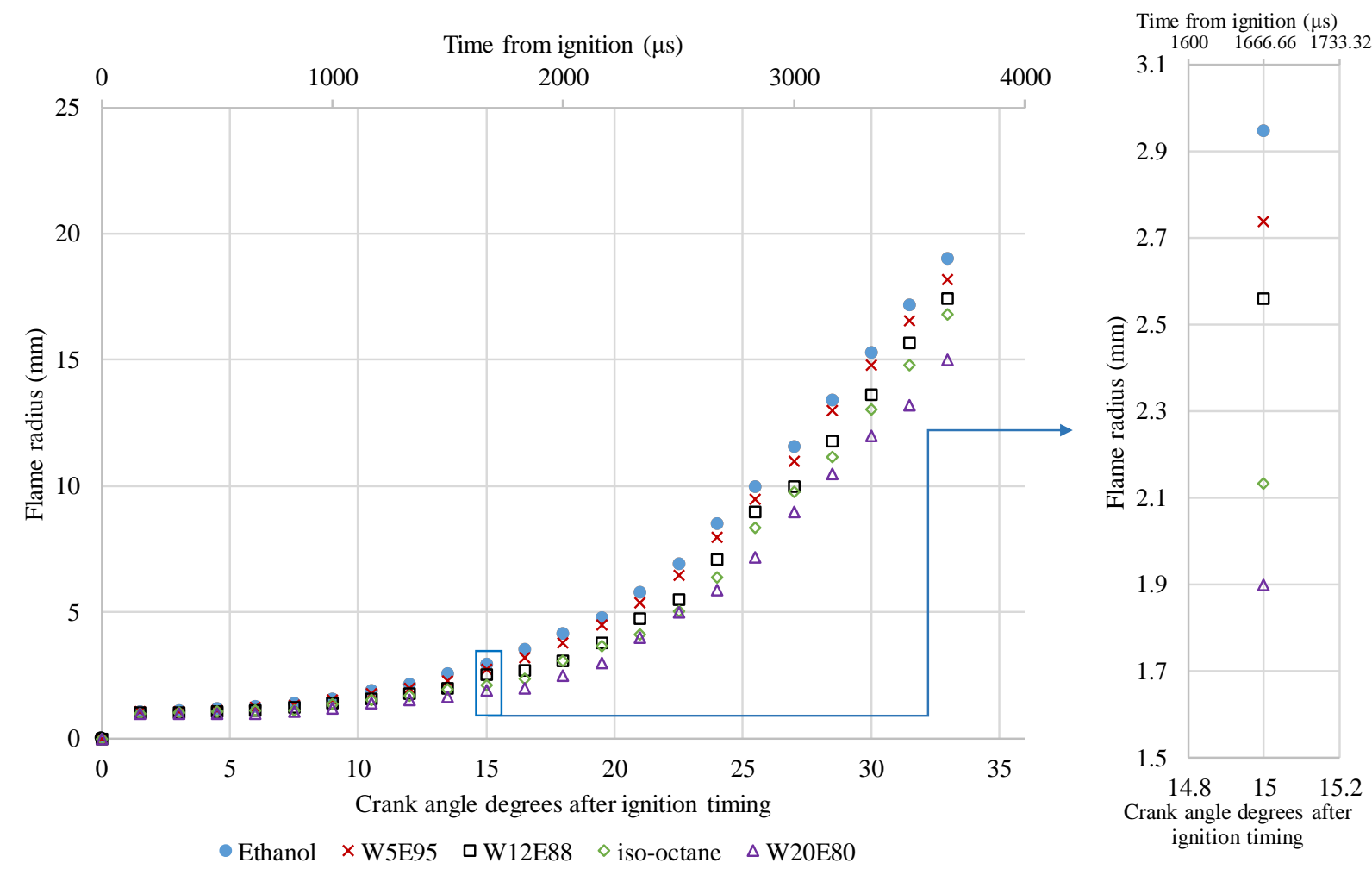

Figure 9. Flame radius for the "mean" visual cycles and relevant fastest and slowest cycle (60 cycles).

Shown in Figure 10 are corresponding computations of shape factor for the mean cycles. The slower burning W20E80 fuel was subjected to the turbulent spectrum for a prolonged period, which resulted in increased distortion of the mean flame shape as the larger scales of turbulence were encroached towards the end of the visible propagation event. The observation of increased bulk flame distortion leading to slower burning suggests the detrimental effects of flame stretch cancel out any benefits of a larger enflamed area due to higher distortion. This may be associated with the flame tendency to migrate towards the hotter exhaust side of the engine. Recent prior PLIF and emissions measurement work [28] with similar fuels and similar operating conditions indicate the fuel-air charge distribution can be considered to be homogenous in this engine. This observation also compounds the likelihood of the hotter exhaust temperatures leading to the observed flame centroid migration. The flame can only be wrinkled by scales of turbulence smaller than the flame itself; initially, the flame is only wrinkled by the smallest scales of turbulence, larger scales merely convect and distort the flame rather than directly increasing enflamed area. As the kernel develops the larger turbulent scales wrinkle the flame until it reaches a fully developed state. where the entire turbulent spectrum can wrinkle the flame [38]. 


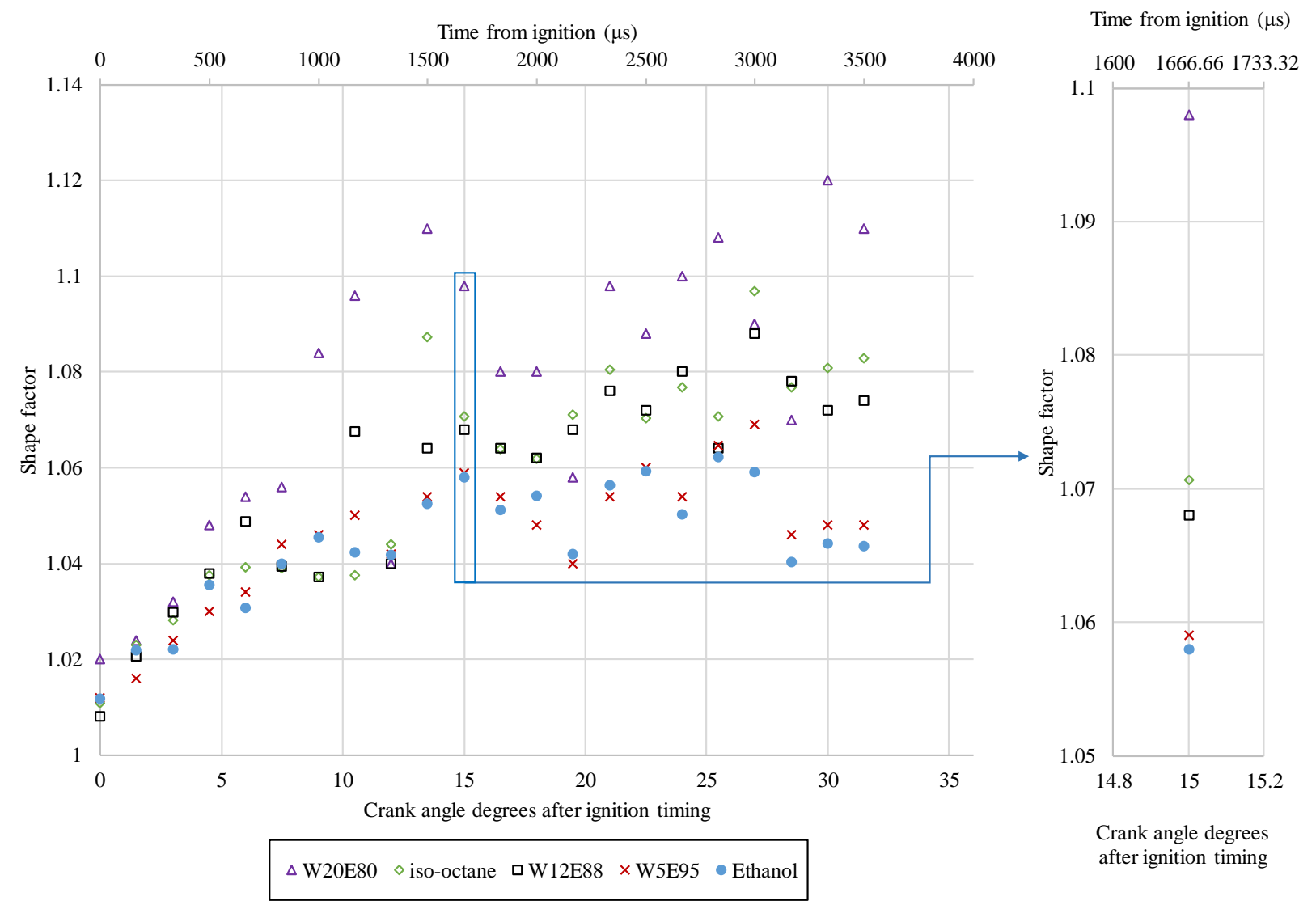

Figure 10. Computed shape factor closest data to 60 averaged cycles.

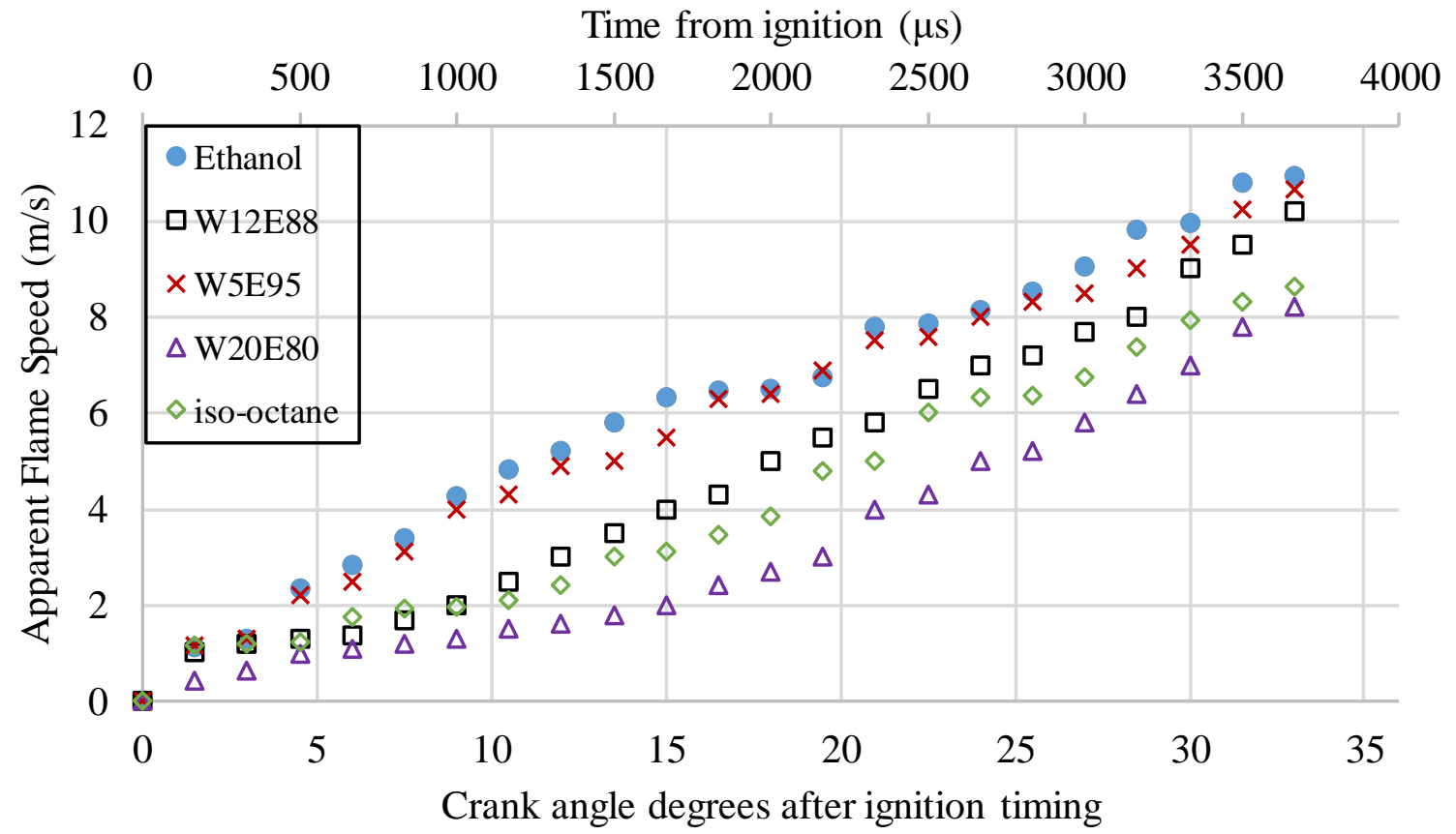

Figure 11. Apparent flame speed closest data to 60 averaged cycles. 
The apparent flame speed shown in Figure 11 is also in good agreement with prior observations, indicating the highest flame speed of $10.93 \mathrm{~m} / \mathrm{s}$ for ethanol and lowest (peak) speed of $8.2 \mathrm{~m} / \mathrm{s}$ for W20E80. The maximum flame speed of $8.2 \mathrm{~m} / \mathrm{s}$ was achieved at 33 CAD AIT for W20E80 (the same flame speed achieved at 24 CAD AIT for ethanol in comparison).

Figure 12 shows the average flame Euclidean distance from the spark plug until one frame (1.5 CAD) before the flame (W20E88) reaches the window periphery. This figure demonstrates a similar trend for all fuels, where the flames grew initially towards the exhaust side of the engine in agreement with previous studies [28]. The ethanol flame contour moved away from its centre by 6.7 $\mathrm{mm}$ in $\mathrm{y}$ and $1 \mathrm{~mm}$ in $\mathrm{x}$-direction total of $7.7 \mathrm{~mm}$, compared to W5E95 (y=6.95 mm, $\mathrm{x}=1.2 \mathrm{~mm}$ total of 8.15), W12E88 (y=6.88 $\mathrm{mm}, \mathrm{x}=1.6 \mathrm{~mm}$ total of $8.48 \mathrm{~mm}), \mathrm{W} 20 \mathrm{E} 80(\mathrm{y}=8 \mathrm{~mm}, \mathrm{x}=5.5 \mathrm{~mm}$ total of $13.5 \mathrm{~mm})$ and iso-octane $(\mathrm{y}=9.6 \mathrm{~mm}, \mathrm{x}=1.73 \mathrm{~mm}$ total of 11.33). This indicates that $5 \%$ water in ethanol (W5E95) is $5.84 \%$ less resistant to flame centroid displacement and flame stretching compared to pure ethanol. Otherwise, 12\% (W12E88) and 20\% (W20E80) water in ethanol indicated noticeably less resistance to flame centroid displacement and flame stretching compared to ethanol (by 10.15 and $75 \%$ respectively). The iso-octane case has higher flame distortion than ethanol and wet ethanol of 5\% and $12 \%$ water content, which is also is in a good agreement with the flame stretch analysis in previous work $[19,20,42]$. 


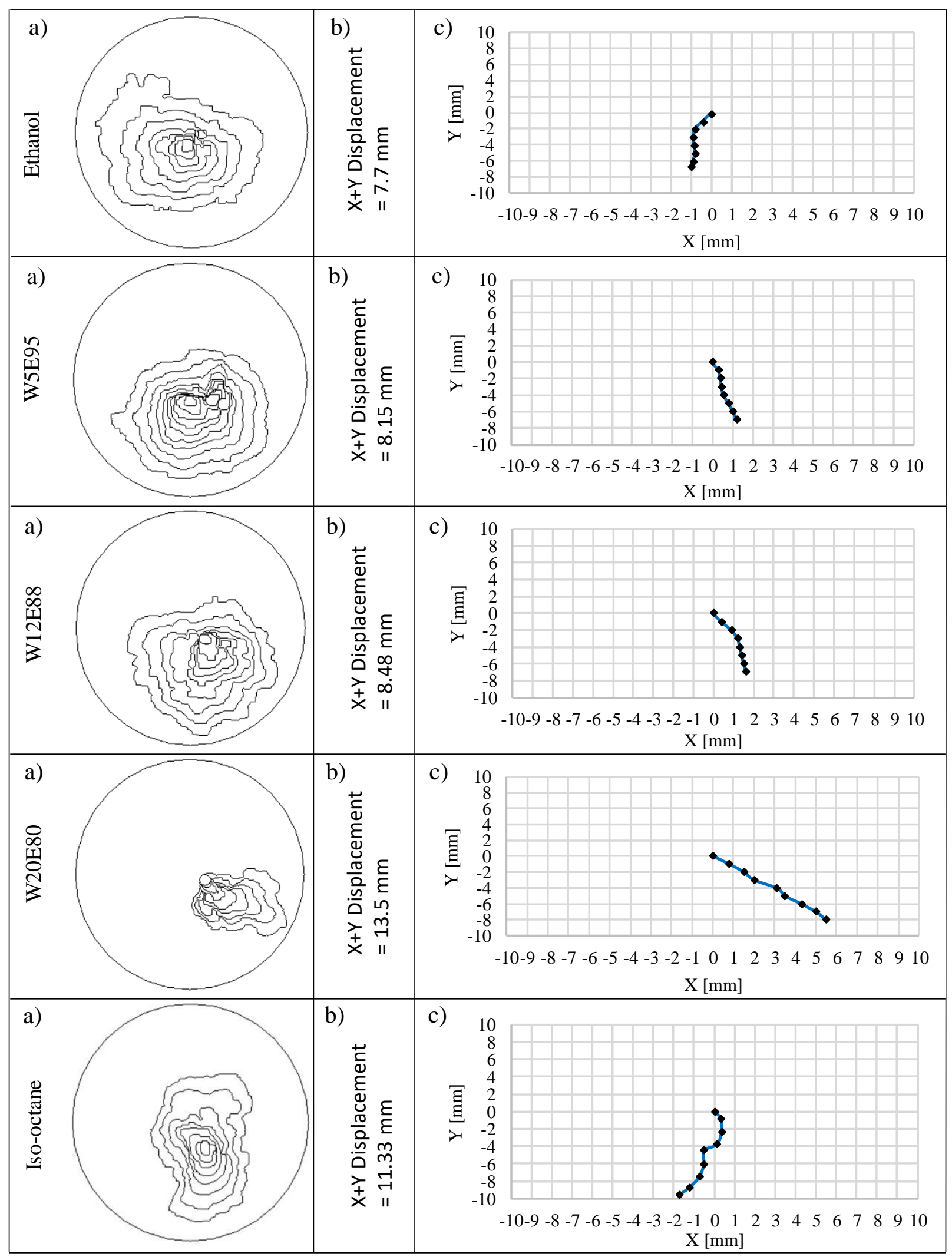

Figure 12. a) Flame contour for Ethanol, W5E95, W12E88 and W20E80 closest to 60 averaged flames. b) Total flame distortion in both horizontal and vertical directions c) Euclidean centroid displacement measurement for all 4 fuels closest to 60 averaged flames. $(x=0, y=0)$ indicating spark position. 


\section{CONCLUSIONS}

Two-dimensional Particle Image Velocimetry (PIV) and flame image analysis has been undertaken and compared to CFD k- $\varepsilon$ RNG modelling to understand the interaction of the in-cylinder flow and flame with "wet" ethanol fuels in a modern spark ignition engine. A cycle selection process was developed to provide a robust means to help select "typical" fast, mean and slow-burning cycles. Under the part-load engine operating conditions tested, the following conclusions were made:

- $\quad$ PIV experiments indicated that the mean flow-field for this engine on the imaged swirl plane is nearly symmetrical across four divided zones of the combustion chamber at the time of combustion initiation.

- Comparisons between PIV and CFD data showed very similar velocity magnitudes as the end of compression was approached. At earlier crank angle timings (e.g. $90^{\circ}$ CA BTDC) the CFD results showed a clear difference from the measured values of velocity (associated with the observed persisting bulk air flow structures in the real engine).

- Comparing the flame radius development of 60 averaged cycles, ethanol exhibited the faster flame propagation, the rate of mass burning and in-cylinder pressure development was in good agreement with burning velocity correlations within the literature.

- By adding 5\% water to ethanol the combustion appeared to be marginally slower. An attempt was made to compare these results with recent hydrous laminar burning velocity correlations, which were in good agreement.

- By adding $20 \%$ water to ethanol the combustion appeared to be noticeably slower with a considerable increase in flame shape distortion as quantified by shape factor values.

- The flame images obtained with all fuels showed a tendency for biased flame growth towards the exhaust valves. The PIV flow field showed no bulk motion toward the exhaust in the imaging plane. The use of pure ethanol resulted in faster combustion and higher resistance to flame migration. This benefit diminished with the addition of water, in good agreement with recent laminar burning velocity correlations for hydrous ethanol.

- Of the blends tested, a water in ethanol content $(\mathrm{v} / \mathrm{v})$ of $12 \%$ is considered to represent a maximum tolerable limit in terms of flame distortion, with $7 \%$ slower flame speed and $10.14 \%$ more flame distortion in comparison to pure ethanol but similar distortion to an iso-octane baseline case.

- Prior research has indicated adequate charge homogeneity in this engine during such operation [28]. Larger scales of turbulence around the spark plug may have been responsible for the migration of flame towards the exhaust, however, it is believed that any remaining large-scale tumble would still have manifested in higher velocities in the horizontal imaging plane. This phenomenon was therefore likely associated with the hotter wall temperatures at the exhaust side of the bore.

The currently reported research indicates that the spark plug would ideally be biased further towards the intake side to enable more equal flame propagation. Such effects may become crucial under high load 
knocking conditions. However, in reality, the plug location is often restricted by intake valve sizing and the need for the cooling jacket to cool both the plug and central injector tip. Future work will consider higher loads and elevated compression ratios. The part load work should also be repeated with a wider suite of fuels under both fixed spark and MBT conditions.

\section{REFERENCES}

[1] IEA. CO2 emissions from fuel combustion: Highlights; 2017. n.d.

[2] Runge P, Sölch C, Albert J, Wasserscheid P, Zöttl G, Grimm V. Economic comparison of different electric fuels for energy scenarios in 2035. Appl Energy 2019;233:1078-93.

[3] Varone A, Ferrari M. Power to liquid and power to gas: an option for the German Energiewende. Renew Sustain Energy Rev 2015;45:207-18.

[4] Schemme S, Samsun RC, Peters R, Stolten D. Power-to-fuel as a key to sustainable transport systems-An analysis of diesel fuels produced from $\mathrm{CO} 2$ and renewable electricity. Fuel 2017;205:198-221.

[5] «E-FUELS» STUDY - The potential of electricity-based fuels for low-emission transport in the EU n.d.

[6] Ladisch MR, Dyck K. Dehydration of ethanol: new approach gives positive energy balance. Science 1979;205:898-900. doi:10.1126/science.205.4409.898.

[7] Flowers DL, Aceves SM, Frias JM. Improving Ethanol Life Cycle Energy Efficiency by Direct Utilization of Wet Ethanol in HCCI Engines. SAE Tech. Pap., 2007, p. 1070-8. doi:10.4271/200701-1867.

[8] Mack JH, Aceves SM, Dibble RW. Demonstrating direct use of wet ethanol in a homogeneous charge compression ignition $(\mathrm{HCCl})$ engine. Energy 2009;34:782-7.

doi:10.1016/j.energy.2009.02.010.

[9] López-Plaza EL, Hernández S, Barroso-Muñoz FO, Segovia-Hernández JG, Aceves SM, MartínezFrías J, et al. Experimental and theoretical study of the energy savings from wet ethanol production and utilization. Energy Technol 2014;2:440-5. doi:10.1002/ente.201300180.

[10] Saffy H a, Northrop WF, Kittelson DB, Boies AM. Energy, carbon dioxide and water use implications of hydrous ethanol production. Energy Convers Manag 2015;105:900-7. doi:10.1016/j.enconman.2015.08.039.

[11] Lanzanova TDM, Dalla Nora M, Zhao H. Performance and economic analysis of a direct injection spark ignition engine fueled with wet ethanol. Appl Energy 2016;169:230-9. doi:10.1016/j.apenergy.2016.02.016. 
[12] Brewster S, Railton D, Maisey M, Frew R. The Effect of E100 Water Content on High Load Performance of a Spray Guide Direct Injection Boosted Engine. SAE Tech. Pap., 2007. doi:10.4271/2007-01-2648.

[13] Lanzanova TDM, Vielmo HA, Sari RL, Dornelles HM, Tatsch GA, Martins MES, et al. Performance Analysis of a Spark Ignited Engine Running on Different Water-in-Ethanol Mixtures. SAE Tech. Pap., 2013. doi:10.4271/2013-36-0202.

[14] Chuepeng S, Srisuwan S, Tongroon M. Lean hydrous and anhydrous bioethanol combustion in spark ignition engine at idle. Energy Convers Manag 2016;128:1-11. doi:10.1016/j.enconman.2016.09.059.

[15] Sari RL, Golke D, Enzweiler HJ, Santos KF, Salau NPG, Martins MES. Investigation of Compression Ratio Effect on Wet Ethanol Use in Spark Ignition Engines. SAE Tech Pap 2017.

[16] Munsin R, Laoonual Y, Jugjai S, Imai Y. An experimental study on performance and emissions of a small SI engine generator set fuelled by hydrous ethanol with high water contents up to $40 \%$. Fuel 2013;106:586-92. doi:10.1016/j.fuel.2012.12.079.

[17] Morganti K, Almansour M, Khan A, Kalghatgi G, Przesmitzki S. Leveraging the benefits of ethanol in advanced engine-fuel systems. Energy Convers Manag 2018;157:480-97. doi:10.1016/j.enconman.2017.11.086.

[18] Augoye A, Aleiferis P. Characterization of Flame Development with Hydrous and Anhydrous Ethanol Fuels in a Spark-Ignition Engine with Direct Injection and Port Injection Systems. SAE Tech. Pap., 2014. doi:10.4271/2014-01-2623.

[19] Parag S, Raghavan V. Experimental investigation of burning rates of pure ethanol and ethanol blended fuels. Combust Flame 2009;156:997-1005. doi:10.1016/j.combustflame.2008.10.011.

[20] Eisazadeh-Far K, Moghaddas A, Al-Mulki J, Metghalchi H. Laminar burning speeds of ethanol/air/diluent mixtures. Proc Combust Inst 2011;33:1021-7. doi:10.1016/j.proci.2010.05.105.

[21] Lawler B, Splitter D, Szybist J, Kaul B. Thermally Stratified Compression Ignition: A new advanced low temperature combustion mode with load flexibility. Appl Energy 2017;189:122-32. doi:10.1016/j.apenergy.2016.11.034.

[22] Gainey B, Hariharan D, Yan Z, Zilg S, Boldaji MR, Lawler B. A split injection of wet ethanol to enable thermally stratified compression ignition. Int J Engine Res 2018:1-13. doi:https://doi.org/10.1177/1468087418810587.

[23] Rahimi Boldaji M, Gainey B, Lawler B. Thermally stratified compression ignition enabled by wet ethanol with a split injection strategy: A CFD simulation study. Appl Energy 2019. doi:10.1016/j.apenergy.2018.11.009.

[24] Sari RL, Golke D, Enzweiler HJ, Salau NPG, Pereira FM, Martins MES. Exploring optimal operating conditions for wet ethanol use in spark ignition engines. Appl Therm Eng 2018;138:523-33. doi:10.1016/j.applthermaleng.2018.04.078.

[25] Asthana S, Bansal S, Jaggi S, Kumar N. A Comparative Study of Recent Advancements in the Field of Variable Compression Ratio Engine Technology. SAE Tech. Pap., 2016. doi:10.4271/2016-010669. 
[26] Wittek K, Geiger F, Andert J, Martins M, Oliveira M. An Overview of VCR Technology and Its Effects on a Turbocharged DI Engine Fueled with Ethanol and Gasoline, 2017. doi:10.4271/201736-0357.

[27] Masum BM, Masjuki HH, Kalam MA, Rizwanul Fattah IM, M Palash S, Abedin MJ. Effect of ethanol-gasoline blend on NOx emission in SI engine. Renew Sustain Energy Rev 2013. doi:10.1016/j.rser.2013.03.046.

[28] Liu Q, Cairns A, Zhao H, Anbari Attar M, Cruff L, Blaxill H. The Effects of Charge Homogeneity and Repeatability on Particulates Using the PLIF Technique in an Optical DISI Engine. SAE Int J Engines 2014;7:500-18. doi:10.4271/2014-01-1207.

[29] Aleiferis PG, Serras-Pereira J, Richardson D. Characterisation of flame development with ethanol, butanol, iso-octane, gasoline and methane in a direct-injection spark-ignition engine. Fuel 2013;109:256-78. doi:10.1016/j.fuel.2012.12.088.

[30] Rahman KM, Kawahara N, Tsuboi K, Tomita E. Combustion characteristics of wet ethanol ignited using a focused Q-switched Nd:YAG nanosecond laser. Fuel 2016;165:331-40. doi:10.1016/j.fuel.2015.10.067.

[31] Hinton N, Stone R, Cracknell R, Olm C. Aqueous ethanol laminar burning velocity measurements using constant volume bomb methods. Fuel 2018. doi:10.1016/j.fuel.2017.10.113.

[32] Liang J, Li G, Zhang Z, Xiong Z, Dong F, Yang R. Experimental and Numerical Studies on Laminar Premixed Flames of Ethanol-Water-Air Mixtures. Energy \& Fuels 2014;28:4754-61.

[33] Beeckmann J, Röhl O, Peters N. Numerical and Experimental Investigation of Laminar Burning Velocities of iso-Octane, Ethanol and n-Butanol. SAE Int 2009. doi:10.4271/2009-01-2784.

[34] Beeckmann J, Kruse S, Peters N. Effect of Ethanol and n-Butanol on Standard Gasoline Regarding Laminar Burning Velocities. Int Powertrains, Fuels Lubr Meet 2010. doi:10.4271/2010-01-1452.

[35] Raffel M, Willert CE, Wereley ST, Kompenhans J. Particle Image Velocimetry: A Practical Guide. vol. 2nd. 2007. doi:10.1097/JTO.0b013e3182370e69.

[36] Raffel M, Willert CE, Kompenhans J. Particle Image Velocimetry. Berlin, Heidelberg, Heidelberg: Springer Berlin Heidelberg; 1998. doi:10.1007/978-3-662-03637-2.

[37] Moslemin Koupaie M, Cairns A, vafamehr H, Lanzanova T. Cyclically Resolved Flame and Flow Imaging in an SI Engine Operating with Future Ethanol Fuels. WCX ${ }^{\mathrm{TM}} 17 \mathrm{SAE}$ World Congr. Exp., vol. 2017-March, SAE International; 2017. doi:https://doi.org/10.4271/2017-01-0655.

[38] Moxey BG, Cairns A, Zhao H. A Study of Turbulent Flame Development with Ethanol Fuels in an Optical Spark Ignition Engine. SAE Pap 2014. doi:10.4271/2014-01-2622.Copyright.

[39] Malcolm J, Behringer M, Aleiferis P, Mitcalf J, OudeNijeweme D. Characterisation of Flow Structures in a Direct-Injection Spark-Ignition Engine using PIV, LDV and CFD. SAE Tech Pap 201101-1290 2011. doi:10.4271/2011-01-1290.

[40] Moxey BG, Cairns A, Zhao H. A comparison of butanol and ethanol flame development in an optical spark ignition engine. Fuel 2016;170:27-38. doi:10.1016/j.fuel.2015.12.008.

[41] Aleiferis PG, Malcolm JS, Todd AR, Cairns A. An Optical Study of Spray Development and Combustion of Ethanol, Iso-Octane and Gasoline Blends in a DISI Engine. SAE Tech Pap 
2008;2008:776-90. doi:10.4271/2008-01-0073.

[42] Brequigny P, Mounaïm-Rousselle C, Halter F, Moreau B, Dubois T. Impact of Fuel Properties and Flame Stretch on the Turbulent Flame Speed in Spark-Ignition Engines. SAE Tech Pap 2013. doi:10.4271/2013-24-0054.

\section{Definitions/Abbreviations}

$\mathbf{u}^{\prime}$

ATDC

AV

BDC

BTDC

CA

CA_Pmax

CA50

CAD AIT

CFD

COV

DISI

EMOP

fps

I
RMS of the deviations

After top dead centre.

Average velocity.

Bottom dead centre

Before top dead centre.

Crank angle

Crank angle location of maximum pressure.

Crank angle location of 50\% mass fraction burned.

Crank angle degree after ignition timing.

Computational fluid dynamics.

Coefficient of variation.

Direct injection spark ignition.

Exhaust maximum opening point.

Frame per second.

Intensity. 


\begin{tabular}{|c|c|}
\hline ICCD & Intensifier charged-couple device \\
\hline IMOP & Intake maximum opening point. \\
\hline MBT & Minimum spark advance for Best \\
\hline PIV & Particle image velocimetry. \\
\hline Pmax & Maximum pressure. \\
\hline RMS & Root mean square. \\
\hline RNG & Re-Normalisation group theory. \\
\hline RPM & Revolution per minute. \\
\hline TDC & Top dead centre. \\
\hline TI & Turbulence intensity. \\
\hline W12E88 & $12 \%$ water in Ethanol. \\
\hline W20E80 & $20 \%$ water in Ethanol. \\
\hline W5E95 & $5 \%$ water in Ethanol. \\
\hline $\mathbf{U}$ & Average velocity. \\
\hline
\end{tabular}

